\title{
Assessment of a Simplified Wheel/Rail Contact Model and Kalker's Linear Theory from the Perspective of Hunting Instability
}

\author{
Osman Taha ŞEN (D) \\ Istanbul Technical University, Department of Mechanical Engineering, Istanbul, Turkey \\ senos@itu.edu.tr
}

(Alınış/Received: 14.01.2021, Kabul/Accepted: 07.05.2021, Yayımlama/Published: 31.07.2021)

\begin{abstract}
This paper investigates the performance of a simplified wheel/rail contact modeling approach that can be implemented to dynamics analysis of railway vehicles. The scope is limited to a two-axle bogie system and the problem is investigated from the hunting instability perspective. Accordingly, a mathematical model of a two-axle bogie with elastically connected wheelsets is developed. The governing equations of the proposed four degree of freedom mathematical model are obtained. These equations are then first solved analytically by considering a simplified approach for the interfacial forces at the wheel/rail contact interface. Second, the contact forces are calculated by using Kalker's linear theory, and the corresponding nonlinear governing equations are solved numerically. Based on the results, it is observed that the analytical and numerical solutions show a good match. Hence, it is concluded that the simplified wheel/rail contact modeling approach can represent the dynamics of the system successfully, especially when the system is in a stable state for hunting behavior. Third, the corresponding eigenvalue problem is formulated from the linear equations, and complex eigenvalues are calculated over the operational speed range of the bogie. It is observed that the natural frequencies of the system are speed-dependent, and either one or both of the wheelsets may become unstable at certain parameter sets. Finally, stability maps are generated for several parameters, and a better understanding of the effects of system parameters on the stability of two-axle bogie is obtained.
\end{abstract}

Keywords: Wheel/Rail contact modeling, Hunting instability, Critical speed

\section{Basitleştirilmiş Tekerlek/Ray Temas Modelinin ve Kalker Doğrusal Teorisinin Demiryolu Taşıtı Sinüs Hareketi Kararlılığı Açısından Değerlendirilmesi}

Öz: $\mathrm{Bu}$ makalede, demiryolu taşıtlarının dinamik analizinde kullanılabilecek basitleştirilmiş bir tekerlek/ray temas modelinin performansı incelenmiştir. Bu amaçla, makalenin kapsamı iki tekerlek takımına sahip bir boji sistemi ile sınırlı tutulmuştur ve problem demiryolu taşıtının sinüs hareketi kararsızlığı açısından incelenmiştir. Buna göre, elastik olarak birbirine bağlı olan iki tekerlek takımına sahip bir bojinin matematiksel modeli geliştirilmiştir ve önerilen dört serbestlik dereceli matematiksel modelin hareket denklemleri elde edilmiştir. Bu denklemler ilk olarak tekerlek/ray temas arayüzündeki temas kuvvetlerinin basitleştirilmiş bir yaklaşım kullanılarak hesaplanması ile analitik olarak çözülmüştür. Daha sonra, temas kuvvetleri Kalker doğrusal teorisi kullanılarak hesaplanmıştır ve doğrusal olmayan hareket denklemleri sayısal olarak çözülmüştür. Analitik ve sayısal olarak elde edilen sonuçlar karşılaştırıldığında çözümlerin iyi bir şekilde eşleştiği görülmüştür. Bu nedenle, basitleştirilmiş tekerlek/ray temas modelleme yaklaşımının, özellikle sistemin sinüs hareketi davranışı açısından kararlı bir durumda olması halinde, sistemin dinamiğini başarılı bir şekilde temsil edebileceği sonucuna varılmıştır. Daha sonra, doğrusal hareket denklemlerinden elde edilen özdeğer problemi ile sistemin karmaşık özdeğerleri, bojinin operasyonel hız aralığı üzerinde hesaplanmıştır. Sistemin doğal frekanslarının hıza bağlı olduğu ve tekerlek takımlarından birinin veya her ikisinin belirli parametre setlerinde dinamik olarak kararsız hale gelebileceği gözlenmiştir. Son olarak, farklı parametreler için kararlılık haritaları üretilmiştir ve sistem parametrelerinin iki tekerlek takımına sahip bojinin dinamik kararlılığı üzerindeki etkileri daha iyi anlaşılmıştır.

Anahtar kelimeler: Tekerlek/ray temas modellemesi, Ray taşıtı sinüs hareketi, Kritik hız 


\section{Introduction}

Kinematic relationships between rails and wheelsets due to their geometric forms cause the railway vehicles to exhibit an interesting oscillatory dynamic behavior. This self-excited vibratory motion is also known as hunting oscillation, and it is first described by Stephenson [1] as "an oscillatory but easy motion of the wheelset on the rails". Major factors leading to this motion are given as: 1) Conicity of the wheels; 2) Nonconservative creep forces at rail/wheel contact interfaces, and 3) Force interactions between wheelset and bogie over the suspension system [2, 3]. At higher speeds, hunting oscillations can become unstable, and thus the railway vehicles cannot operate above determined critical speeds. Therefore, the critical speed of the vehicle should be reasonably high in order to increase the operational speed range.

Hunting instability has been extensively investigated by many researchers and several techniques have been employed in order to determine the critical speed of the vehicle. In one study by Wickens [3], it is suggested to reduce inertia of the wheelset, increase the stiffness of the suspension system, etc. in order to increase the critical speed. Lee and Cheng [4] investigated hunting phenomenon through a linear 10 DOF model where Kalker's linear theory is used for the wheel/rail contact modeling. In this study, effects of several parameters (such as longitudinal/lateral stiffness of the primary suspension system, longitudinal/lateral damping of the secondary suspension system) on critical speed are investigated. Results are compared to a former 6 DOF formulation and it is observed that the 6 DOF model overestimates the critical speed. Furthermore, authors claim that the wheels with new treads (lower conicity) increase the critical speed, hence the critical speed reduces with aging due to the change in conicity. In yet another study by Lee and Cheng [5], an 8 DOF mathematical model of a half truck is developed with a single bogie including two wheelsets. In the model, the wheel/rail contact interface is modeled with the heuristic nonlinear creep model and authors observe that the longitudinal stiffness of the primary stiffness is an important parameter from the perspective of hunting instability. Cheng et al. [6] investigated the problem with a 21 DOF nonlinear model of single truck with two bogies. Similarly, the heuristic creep model is adopted for the modeling of the wheel/rail contact interface. This model is further simplified to different submodels (6 DOF, 14 DOF and 20 DOF) through certain assumptions and the investigation is conveyed accordingly. It is observed that the critical speeds for the 6 DOF and 14 DOF models during curving are higher than those evaluated from the 20 DOF model. In addition, the critical speeds obtained using the heuristic nonlinear creep model are generally lower than those obtained from Kalker's linear creep model. Furthermore, vertical stiffness and damping of the secondary suspension system are found to be important parameters that are effective on the critical speed. Finally, it is observed that the critical speed increases with the increase of the curve radius. Shabana et al. [7] studied the effect of wheel/rail geometric properties on the stability of railroad vehicles. Thus, two computational models (a constrained wheelset model and full nonlinear truck model) are proposed and the investigation is carried out on two different contact formulations. Authors conclude that the wheel profile may have a significant effect on critical speed. Moreover, it is stated that the contact model that allows only single point contact at wheel/rail interface leads to lower critical speeds due to its higher conicity. Kim et al. [8] developed a 31 DOF truck model with two bogies including two wheelsets at each. In the model, the heuristic creep model is used for wheel/rail contact interface and flange contact is also taken into consideration. Authors claim that the critical speed is highly sensitive to stiffness parameters of the primary suspension system and damping coefficients of the secondary suspension system. Furthermore, the nonlinear heuristic creep model is found to be crucial for the estimation of critical speed. Taheri and Ahmedian [9] developed a computational model of a bogie with two wheelsets and investigated the effect of system parameters on the hunting stability. It is observed that the friction coefficient at the carbody/bolster contact interface is the most significant parameter that alters the critical speed. Furthermore, authors claim that the critical speed estimated by a linear model using eigenvalue calculations are higher than the critical speed predicted by the nonlinear model in the time domain. Park et al. [10] investigated the 
hunting dynamics of a 14 DOF truck model with two bogies and four wheelsets. Numerical results are obtained for both linearized and linear Kalker models and it is observed that the critical speeds of the linear Kalker model are slightly less than those of the linearized model. Furthermore, authors claim that the influences of the suspension parameters on the critical speeds are less than expected due the values of the suspension parameters being high. Hence, the model responded to wheel/rail contact characteristics with a higher sensitivity than suspension parameters. Nath and Jayadev [11] studied the dynamics of the wheelset with a nonlinear mathematical model, and suggest that an increase in the yaw stiffness shifts the critical speed to higher values.

The main goal of this study is to investigate the performance of a simplified wheel/rail contact modeling approach through a two-axle bogie model. The time domain responses obtained with this approach are then compared with Kalker's linear theory. Finally, a parametric stability analysis is conveyed in order to understand the effects of system parameters. Hence the objectives of the current paper are: 1) Develep a four degree of freedom model of a two-axle bogie, and obtain the governing equations of motion; 2) Develop a simplified approach for interfacial contact forces at wheel/rail contact interfaces and calculate the time histories analytically; 3) Implement Kalker's linear theory for interfacial contact force calculation, and solve the corresponding nonlinear governing equations numerically; and 4) Formulate the corresponding eigenvalue problem, and observe the stability of the bogie for different parameter sets.

\section{Mathematical Modeling of the Two-Axle Bogie}

Schematic of the two-axle bogie model is shown in Figure 1. As seen in the figure, the front $\left(m_{f}\right.$, $\left.I_{f}\right)$ and rear $\left(m_{r}, I_{r}\right)$ wheelsets are attached to the bogie with elastic $\left(k_{x}, k_{y}\right)$ and dissipative $\left(c_{x}\right.$, $c_{y}$ ) elements, hence the system has the following four degree of freedom: 1) Lateral displacement of the front wheelset, $y_{f}$;2) Lateral displacement of rear wheelset, $\left.y_{r} ; 3\right)$ Yaw rotation of the front wheelset, $\psi_{f}$; and 4) Yaw rotation of the rear wheelset, $\psi_{r}$. The elastic $\left(k_{x}, k_{y}\right)$ and dissipative $\left(c_{x}, c_{y}\right)$ elements represent the stiffness and damping characteristics of the axleboxes, and they are assumed to be linear in the current study. Furthermore, $s, s_{a}$ and $l$ represent the track width, half of the distance between axleboxes, and the wheelbase, respectively. In this study, the bogie is assumed to move at a constant speed $V$, and the directions of elastic and dissipative forces are assumed to be intact with small angle approximation. Front and rear wheelsets are connected through a linear spring $\left(k_{s}\right)$, a linear damper $\left(c_{s}\right)$ and a torsional spring $\left(K_{b}\right)$ that are referred as shear stiffness, shear damping and bending stiffness, respectively. Finally, all the wheels are assumed to be purely coned and have a nominal conicity $\delta_{0}$, which is a very small number.

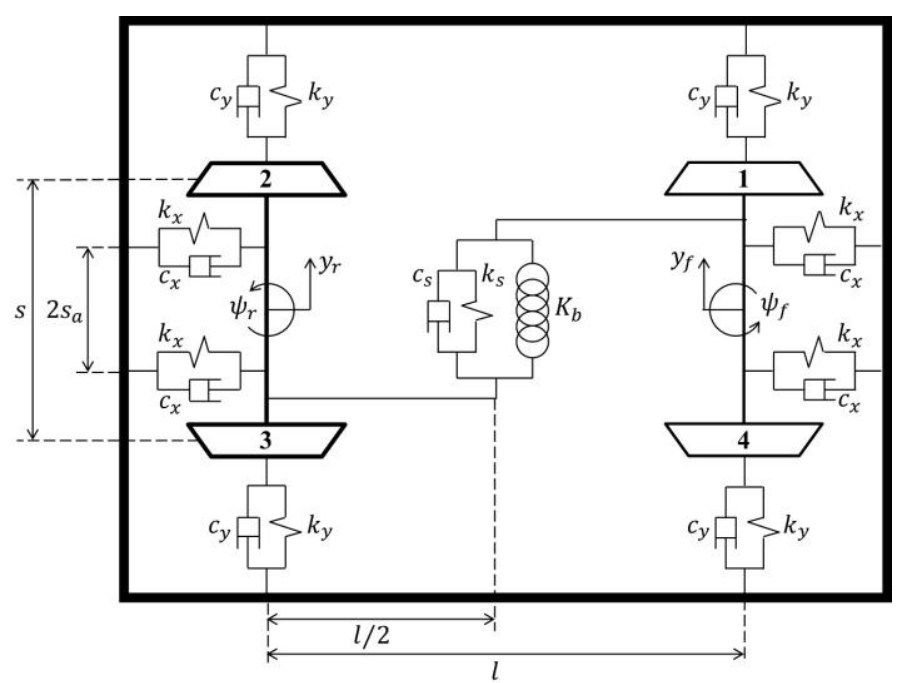

Figure 1. Proposed model of the two-axle bogie 
The governing equations of the system shown in Figure 1 are obtained as follows:

$$
\begin{aligned}
m_{f} \ddot{y}_{f}+\left(2 c_{y}+\right. & \left.c_{s}\right) \dot{y}_{f}-c_{s} \dot{y}_{r}-\frac{c_{s} l}{2}\left(\dot{\psi}_{f}+\dot{\psi}_{r}\right)+\left(2 k_{y}+k_{s}\right) y_{f}-k_{s} y_{r} \\
& -\frac{k_{s} l}{2}\left(\psi_{f}+\psi_{r}\right)+S_{1}+S_{4}=0 \\
m_{r} \ddot{y}_{r}-c_{s} \dot{y}_{f}+ & \left(2 c_{y}+c_{s}\right) \dot{y}_{r}+\frac{c_{s} l}{2}\left(\dot{\psi}_{f}+\dot{\psi}_{r}\right)-k_{s} y_{f}+\left(2 k_{y}+k_{s}\right) y_{r} \\
& +\frac{k_{s} l}{2}\left(\psi_{f}+\psi_{r}\right)+S_{2}+S_{3}=0 \\
I_{f} \ddot{\psi}_{f}-\frac{c_{s} l}{2}\left(\dot{y}_{f}-\right. & \left.\dot{y}_{r}\right)+\left(\frac{c_{s} l^{2}}{4}+2 c_{x} s_{a}^{2}\right) \dot{\psi}_{f}+\frac{c_{s} l^{2}}{4} \dot{\psi}_{r}-\frac{k_{s} l}{2}\left(y_{f}-y_{r}\right) \\
+ & \left(\frac{k_{s} l^{2}}{4}+2 k_{x} s_{a}^{2}+K_{b}\right) \psi_{f}+\left(\frac{k_{s} l^{2}}{4}-K_{b}\right) \psi_{r}-\frac{s}{2}\left(U_{1}-U_{4}\right) \\
= & 0 \\
I_{r} \ddot{\psi}_{r}-\frac{c_{s} l}{2}\left(\dot{y}_{f}-\right. & \left.\dot{y}_{r}\right)+\frac{c_{s} l^{2}}{4} \dot{\psi}_{f}+\left(\frac{c_{s} l^{2}}{4}+2 c_{x} s_{a}^{2}\right) \dot{\psi}_{r}-\frac{k_{s} l}{2}\left(y_{f}-y_{r}\right) \\
+ & \left(\frac{k_{s} l^{2}}{4}-K_{b}\right) \psi_{f}+\left(\frac{k_{s} l^{2}}{4}+2 k_{x} s_{a}^{2}+K_{b}\right) \psi_{r}-\frac{s}{2}\left(U_{2}-U_{3}\right) \\
= & 0
\end{aligned}
$$

where $S_{i}$ and $U_{i}$ are the lateral and longitudinal creep forces that are developed at the wheel/rail contact interfaces. Note that the subscripts $(i=1,2,3,4)$ used to label these forces denote the number of the wheel as also depicted in Figure 1.

In order to evaluate the creep forces $\left(U_{i}\right.$ and $\left.S_{i}\right)$, longitudinal $\left(\xi_{x}\right)$, lateral $\left(\xi_{y}\right)$ and spin $\left(\xi_{s}\right)$ creepages [12] at all wheels are first obtained from the corresponding velocity vectors as follows:

$$
\begin{aligned}
\xi_{x, 1}=-\frac{s \dot{\psi}_{f}}{2 V}-\frac{\delta_{0} y_{f}}{r_{0}}-\frac{l \delta_{0} \psi_{f}}{2 r_{0}} & \xi_{y, 1}=\frac{\dot{y}_{f}}{V}+\frac{l \dot{\psi}_{f}}{2 V}-\psi_{f} & \xi_{s, 1}=\frac{\dot{\psi}_{f}}{V} \\
\xi_{x, 2}=-\frac{s \dot{\psi}_{r}}{2 V}-\frac{\delta_{0} y_{r}}{r_{0}}+\frac{l \delta_{0} \psi_{r}}{2 r_{0}} & \xi_{y, 2}=\frac{\dot{y}_{r}}{V}-\frac{l \dot{\psi}_{r}}{2 V}-\psi_{r} & \xi_{s, 2}=\frac{\dot{\psi}_{r}}{V} \\
\xi_{x, 3}=\frac{s \dot{\psi}_{r}}{2 V}+\frac{\delta_{0} y_{r}}{r_{0}}-\frac{l \delta_{0} \psi_{r}}{2 r_{0}} & \xi_{y, 3}=\frac{\dot{y}_{r}}{V}-\frac{l \dot{\psi}_{r}}{2 V}-\psi_{r} & \xi_{s, 3}=\frac{\dot{\psi}_{r}}{V} \\
\xi_{x, 4}=\frac{s \dot{\psi}_{f}}{2 V}+\frac{\delta_{0} y_{f}}{r_{0}}+\frac{l \delta_{0} \psi_{f}}{2 r_{0}} & \xi_{y, 4}=\frac{\dot{y}_{f}}{V}+\frac{l \dot{\psi}_{f}}{2 V}-\psi_{f} & \xi_{s, 4}=\frac{\dot{\psi}_{f}}{V}
\end{aligned}
$$

where $r_{0}$ is the nominal rolling radius of the wheels. Here, it should be mentioned that wheels in the current study are assumed to be purely conical. Therefore, wheel flange is not modeled, hence the flange contact is not considered.

\section{Analytical Solutions with a Simplified Interfacial Contact Force Modeling Approach}

In order to obtain a set of linear governing equations, creep forces $U_{i}$ and $S_{i}$ are approximated with linear expressions as follows: 


$$
\begin{aligned}
& U_{i}=\mu_{x} Q \xi_{x, i} \\
& S_{i}=\mu_{y} Q \xi_{y, i}
\end{aligned}
$$

Here, $\mu_{x}$ and $\mu_{y}$ are defined as longitudinal and lateral adhesion coefficients. Importing Equations (5) and (6) to the Equations (1) to (4), one can obtain the corresponding equations of motion in linear form as follows:

$$
\begin{gathered}
m_{f} \ddot{y}_{f}+\left(2 c_{y}+c_{s}+\frac{2 \mu_{y} Q}{V}\right) \dot{y}_{f}-c_{s} \dot{y}_{r}+\left(\frac{\mu_{y} Q l}{V}-\frac{c_{s} l}{2}\right) \dot{\psi}_{f}-\frac{c_{s} l}{2} \dot{\psi}_{r} \\
+\left(2 k_{y}+k_{s}\right) y_{f}-k_{s} y_{r}-\left(\frac{k_{s} l}{2}+2 \mu_{y} Q\right) \psi_{f}-\frac{k_{s} l}{2} \psi_{r}=0 \\
m_{r} \ddot{y}_{r}-c_{s} \dot{y}_{f}+ \\
+\left(2 c_{y}+c_{s}+\frac{2 \mu_{y} Q}{V}\right) \dot{y}_{r}+\frac{c_{s} l}{2} \dot{\psi}_{f}+\left(\frac{c_{s} l}{2}-\frac{\mu_{y} Q l}{V}\right) \dot{\psi}_{r}-k_{s} y_{f} \\
+\left(2 k_{y}+k_{s}\right) y_{r}+\frac{k_{s} l}{2} \psi_{f}+\left(\frac{k_{s} l}{2}-2 \mu_{y} Q\right) \psi_{r}=0 \\
I_{f} \ddot{\psi}_{f}-\frac{c_{s} l}{2}\left(\dot{y}_{f}-\dot{y}_{r}\right)+\left(\frac{c_{s} l^{2}}{4}+2 c_{x} s_{a}^{2}+\frac{\mu_{x} Q s^{2}}{2 V}\right) \dot{\psi}_{f}+\frac{c_{s} l^{2}}{4} \dot{\psi}_{r} \\
-\left(\frac{k_{s} l}{2}-\frac{\mu_{x} Q s \delta_{0}}{r_{0}}\right) y_{f}+\frac{k_{s} l}{2} y_{r} \\
+\left(\frac{k_{s} l^{2}}{4}+2 k_{x} s_{a}^{2}+K_{b}+\frac{\mu_{x} Q s l \delta_{0}}{2 r_{0}}\right) \psi_{f}+\left(\frac{k_{s} l^{2}}{4}-K_{b}\right) \psi_{r}=0 \\
I_{r} \ddot{\psi}_{r}-\frac{c_{s} l}{2}\left(\dot{y}_{f}-\dot{y}_{r}\right)+\frac{c_{s} l^{2}}{4} \dot{\psi}_{f}+\left(\frac{c_{s} l^{2}}{4}+2 c_{x} s_{a}^{2}+\frac{\mu_{x} Q s^{2}}{2 V}\right) \dot{\psi}_{r}-\frac{k_{s} l}{2} y_{f} \\
+\left(\frac{k_{s} l}{2}+\frac{\mu_{x} Q s \delta_{0}}{r_{0}}\right) y_{r}+\left(\frac{k_{s} l^{2}}{4}-K_{b}\right) \psi_{f} \\
+\left(\frac{k_{s} l^{2}}{4}+2 k_{x} s_{a}^{2}+K_{b}-\frac{\mu_{x} Q s l \delta_{0}}{2 r_{0}}\right) \psi_{r}=0
\end{gathered}
$$

Observe that Equations (7)-(10) are all second order linear ordinary differential equations, and can be solved analytically. Though, these equations are all coupled; hence they should be solved simultaneously. Note that the analytical solutions of these equations are given in the following sections of the paper while comparing the results to the numerical solutions of nonlinear governing equations.

\section{Numerical Solutions with Kalker's Linear Theory}

Based on Kalker's linear theory [13-16], contact forces are calculated as $U_{i}=a_{i} b_{i} G C_{11} \xi_{x, i}$ and $S_{i}=a_{i} b_{i} G C_{22} \xi_{y, i}+a_{i} b_{i} G C_{23} \xi_{s, i}$ where $a$ and $b$ are the principal radii of the contact ellipse for the corresponding wheel, $G$ is a combined shear modulus of the wheel and rail materials, $C_{11}, C_{22}$ and $C_{23}$ are the Kalker coefficients determined from tables [13-16]. Principal radii $a$ and $b$ are evaluated from the Hertzian contact theory as below [17]:

$$
a_{i}=\alpha_{i} \sqrt[3]{\frac{3 \pi Q\left(K_{1}+K_{2}\right)}{4 K_{3}}}
$$




$$
b_{i}=\beta_{i} \sqrt[3]{\frac{3 \pi Q\left(K_{1}+K_{2}\right)}{4 K_{3}}}
$$

where $Q$ is the normal load on wheels that is assumed to be the same at each wheel, $K_{1}$ and $K_{2}$ are material dependent constants for the wheel and rail, respectively. These constants are calculated as $K_{1}=\left(1-v_{w}^{2}\right) / \pi E_{w}$ and $K_{2}=\left(1-v_{r}^{2}\right) / \pi E_{r}$, where $v$ and $E$ are the Poisson's ratio and elasticity modulus for the contacting bodies, respectively. The parameter $K_{3}$ in Equation (11) depends on the geometric properties of the contacting bodies and defined as follows:

$$
K_{3}=\frac{1}{2}\left(\frac{1}{r_{i}}+\frac{1}{r_{i}^{\prime}}+\frac{1}{r_{r}}+\frac{1}{r_{r}^{\prime}}\right)
$$

where, $r_{i}$ and $r_{r}$ are the principal rolling radii of the $i^{\text {th }}$ wheel and rail at the point of contact, respectively. Furthermore $r_{i}^{\prime}$ and $r_{r}^{\prime}$ are the principal transverse radii of curvature of the $i^{\text {th }}$ wheel and rail at the point of contact, respectively. The coefficients $\alpha_{i}$ and $\beta_{i}$ in Equation (11) are found from the empirical formulas [18] with respect to the nondimensional parameter $\theta$ as below:

$$
\begin{gathered}
\alpha_{i}\left(\theta_{i}\right)=A_{m} \tan \left(\theta_{i}-\frac{\pi}{2}\right)+\frac{B_{m}}{\theta_{i}^{C_{m}}}+D_{m} \\
\beta_{i}\left(\theta_{i}\right)=\frac{1}{A_{n} \tan \left(\theta_{i}-\frac{\pi}{2}\right)+1}+B_{n} \theta_{i}^{C_{n}}+D_{n} \sin \left(\theta_{i}\right)
\end{gathered}
$$

Here, $\theta=\cos ^{-1}\left(K_{4} / K_{3}\right)$ and $K_{4}$ is a coefficient depending on the curvatures of the contacting bodies.

$$
K_{4}=\frac{1}{2} \sqrt{\left(\frac{1}{r_{i}}-\frac{1}{r_{i}^{\prime}}\right)^{2}+\left(\frac{1}{r_{r}}-\frac{1}{r_{r}^{\prime}}\right)^{2}+\left(\frac{1}{r_{i}}-\frac{1}{r_{i}^{\prime}}\right)\left(\frac{1}{r_{r}}-\frac{1}{r_{r}^{\prime}}\right) \cos (2 \phi)}
$$

The parameter $\phi$ in Equation (14) is the angle between the normal planes of the curvatures of the contacting bodies, and $A, B, C$ and $D$ in Equation (13) are empirical constants given in [18].

Observe that the Kalker coefficients $C_{11}, C_{22}$ and $C_{23}$ are determined from the principal radii of contact ellipse $a$ and $b$ (Equation (11)), which depend on the state variables through the parameters $K_{3}$ and $K_{4}$. Therefore, the Kalker coefficients are not constant and are nonlinear functions of the state variables. Consequently, the governing equations given with Equations (1) to (4) become nonlinear and they are solved numerically.

\section{Time Domain Solutions of the Nonlinear and Linear Models}

Time domain responses for the linear (Equations (7)-(10)) and nonlinear (Equations (1)-(4)) are obtained for the two-axle bogie system as depicted in Figure 1. The solutions are obtained at two different speeds of the bogie $(V)$ and corresponding time histories are shown in Figures (2) and (3). 

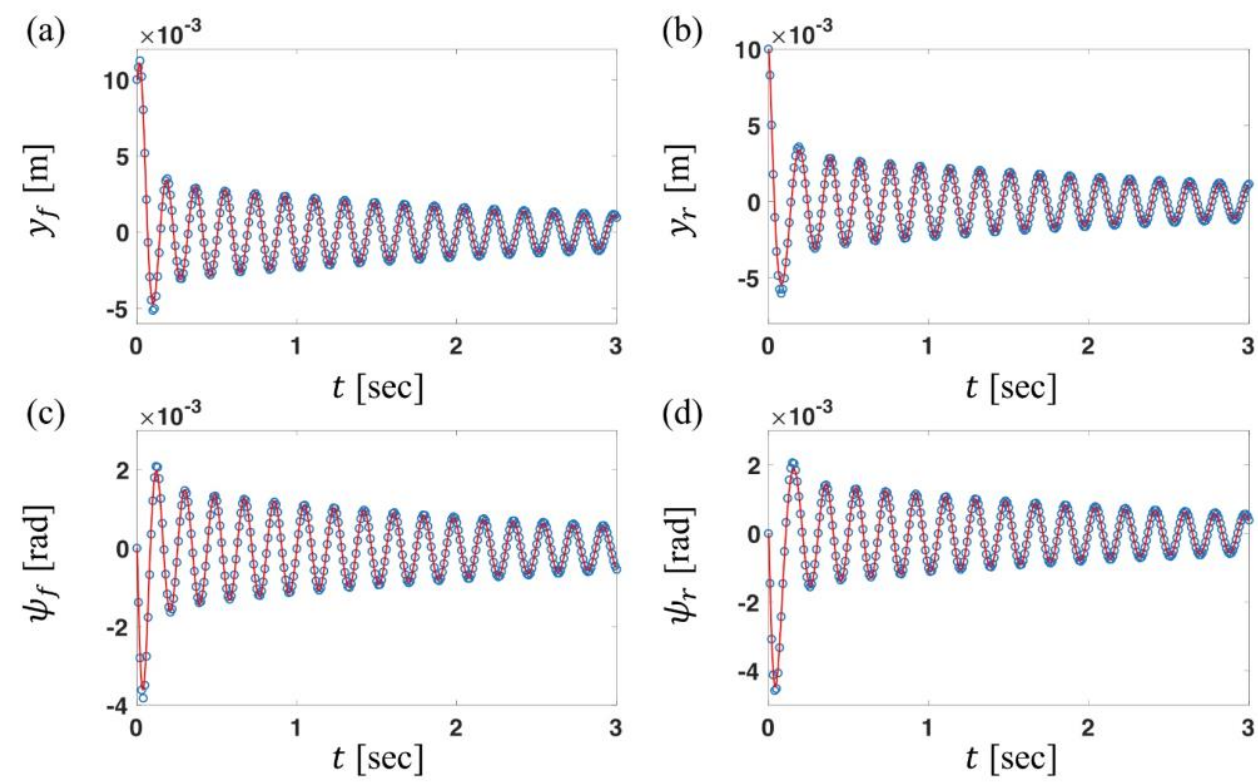

Figure 2. Time domain responses for $V=55 \mathrm{~m} / \mathrm{s}$. (a) $y_{f}$ vs. $t$; (b) $y_{r}$ vs. $t$; (c) $\psi_{f}$ vs. $t$; (d) $\psi_{r}$ vs. $t$. Key:, Nonlinear model, O, Linear model

(a)

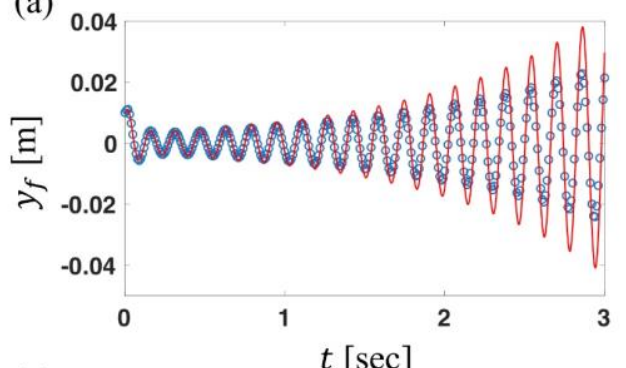

(c)

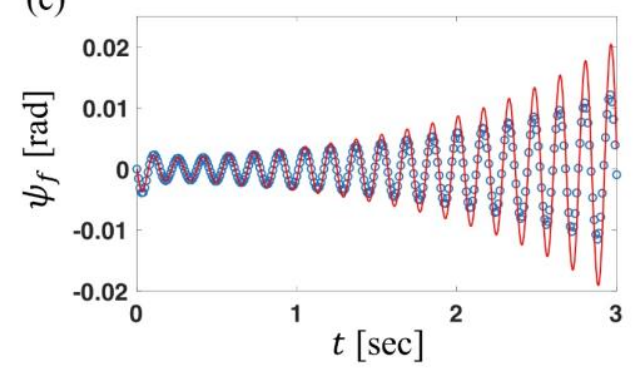

(b)

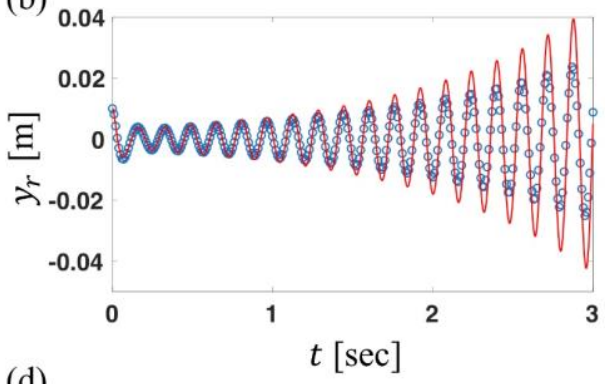

(d)

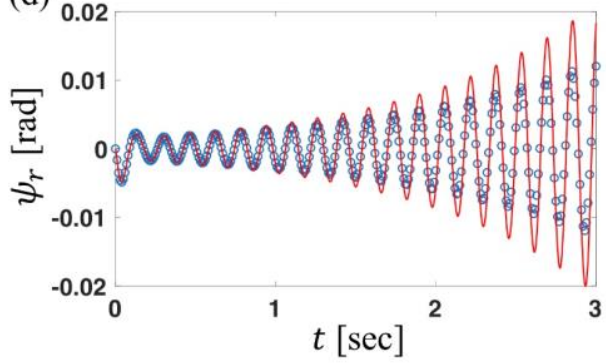

Figure 3. Time domain responses for $V=65 \mathrm{~m} / \mathrm{s}$. (a) $y_{f}$ vs. $t$; (b) $y_{r}$ vs. $t$; (c) $\psi_{f}$ vs. $t$; (d) $\psi_{r}$ vs. $t$.

Key:, Nonlinear model, O, Linear model

The numerical solutions of the nonlinear governing equations are obtained through a $4^{\text {th }}$ order Runge-Kutta technique. First, observe that the lateral displacement and yaw rotation responses are bounded for $V=90 \mathrm{~m} / \mathrm{s}$. Hence, the system is at a stable state. As $V$ increases, response amplitudes increase in time and the system is unstable. This behavior shows that there is a critical speed in between the speed values $90 \mathrm{~m} / \mathrm{s}$ and $100 \mathrm{~m} / \mathrm{s}$, where the bogie goes from a stable to an unstable state. Second, it is seen that the simplified linear approach can successfully represent the dynamics of the nonlinear model, especially at stable region. Though, the simplified linear model underestimates response amplitudes when the bogie is unstable. This is due to Kalker 
coefficients being state variable dependent. In the unstable state, variation of Kalker coefficients is higher due to high response amplitudes; hence these coefficients cannot be represented with a constant as being done in the simplified linear model.

\section{Stability Analysis of the Two-Axle Bogie Model}

Since the simplified linear model and the nonlinear model show a good match, the stability of the system is determined from the complex eigenvalue solution of the linear model. First the Equations (7) to (10) are written in state-space form as below:

$$
\{\dot{\eta}\}=\left[\begin{array}{cc}
0 & I \\
-M^{-1} K & -M^{-1} C
\end{array}\right]\{\eta\}
$$

where $\eta=\left[\begin{array}{llllllll}y_{f} & y_{r} & \psi_{f} & \psi_{r} & \dot{y}_{f} & \dot{y}_{r} & \dot{\psi}_{f} & \dot{\psi}_{r}\end{array}\right]^{T}$ and $M, C$ and $K$ are mass, damping and stiffness matrices, respectively. A close investigation of these matrices reveals that the system is damping and stiffness coupled, and both $C$ and $K$ matrices are asymmetric. Thus, the system is prone to loss of stability. Therefore, the complex eigenvalues are obtained from the Equation (15), and the stability of the system is determined through the real parts of these complex eigenvalues. In other words, a positive real part of a complex eigenvalue $(\lambda)$ corresponds to the unstable state of the given system. First, the speed $(V)$ of the bogie is varied from $55 \mathrm{~m} / \mathrm{s}$ to $65 \mathrm{~m} / \mathrm{s}$ in order to determine the critical speed of the system of Figure 1, and the real parts of the eigenvalues are shown in Figure 4. As seen in the figure, $\operatorname{Re}(\lambda)$ for all eigenvalues are velocity dependent and they increase as $V$ increases, which is also observed by Klingel [19]. Furthermore, one of the $\operatorname{Re}(\lambda)$ is positive for $V>58.66 \mathrm{~m} / \mathrm{s}$. Thus, $V_{c r}=58.66 \mathrm{~m} / \mathrm{s}$ is the critical speed of the bogie.

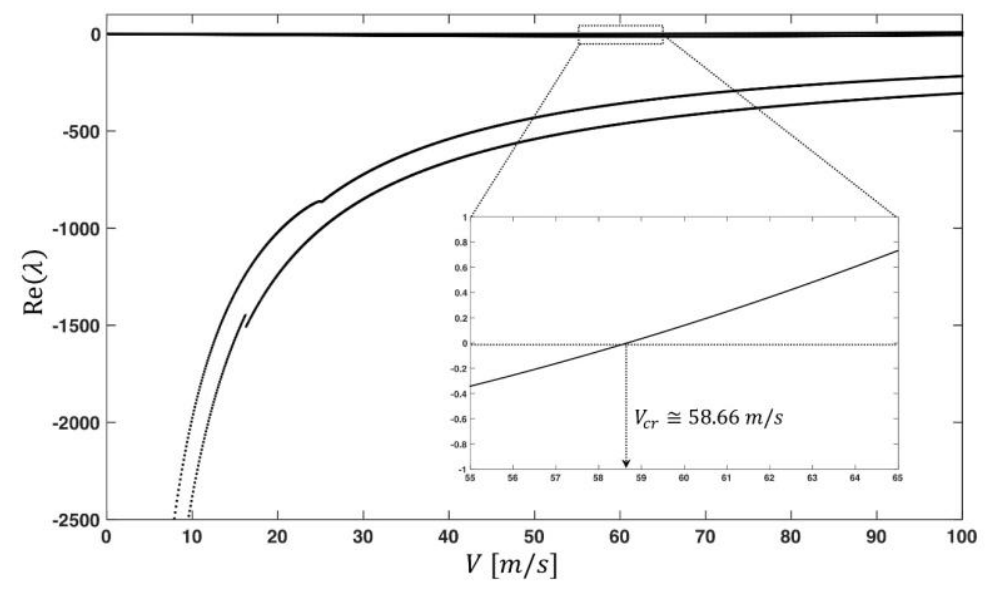

Figure 4. Real parts of calculated eigenvalues with respect to $V$.

In order to further investigate the effects of system parameters on the stability of the proposed bogie model, stability maps in which two parameters are simultaneously varied while others kept intact are generated. In these maps, critical speed thresholds are given for various speed levels, hence the effects of selected parameters on the critical speed is obtained. First, the inertia terms $I_{f}$ and $I_{r}$ are studied and the corresponding stability map is given in Figure 5. As seen in the figure, reducing $I_{f}$ and $I_{r}$ increases $V_{c r}$, which is also suggested by Wickens [3]. In the second case, masses of the front $\left(m_{f}\right)$ and rear $\left(m_{r}\right)$ wheelsets are varied over a given range, and the stability map is shown in Figure 6. Observe that the stability of the system is more sensitive to $m_{r}$ than $m_{f}$, especially at lower speeds. Hence, reducing $m_{r}$ is a more effective solution for increasing $V_{c r}$. In the third case, the effect of axlebox rigidity is investigated by varying $k_{x}$ and 
$k_{y}$ (Figure 7). As opposed to inertial terms, increasing the rigidity of the axlebox seems to increase Vcr. Furthermore, at high critical speeds; the sensitivity of the system stability to $k_{y}$ is higher, which means that the rigidity of the axlebox in lateral direction can alter the system response drastically. In the next case, effect of shear $\left(k_{s}\right)$ and bending $\left(K_{b}\right)$ stiffness on system stability is investigated, and the corresponding stability map is given in Figure 8. Observe that at low $K_{b}$ values and when $K_{b}<k_{s}$, the stability is highly sensitive to $K_{b}$ and changing $k_{s}$ at this parameter region does not change $V_{c r}$. Similarly, at low $k_{s}$ values and when $k_{s}<K_{b}, k_{s}$ is the only parameter that can increase $V_{c r}$. In addition, increasing both $k_{s}$ and $K_{b}$ improves the critical speed, though there seems to be a set of parameters where $V_{c r}$ is at a maximum. A further increase in $k_{s}$ and $K_{b}$ leads to a reduction in $V_{c r}$. Those regions where the critical speed is at maximum locate at high $k_{s}$ - low $K_{b}$ and low $k_{s}-$ high $K_{b}$ values. Note that, similar observations are also suggested by Whitman in [20]. Figure 9 shows the change in $V_{c r}$ with respect to $s_{a}$ and $s$. Increasing both terms shifts the $V_{c r}$ to higher values, though at high $s_{a}$ and low $s$ values, stability becomes independent from $s_{a}$. Finally, effect of $Q$ and $\delta_{0}$ is investigated and the results are shown in Figure 10. Similar to the previous case, again higher $Q$ and $\delta_{0}$ values lead to higher $V_{c r}$.

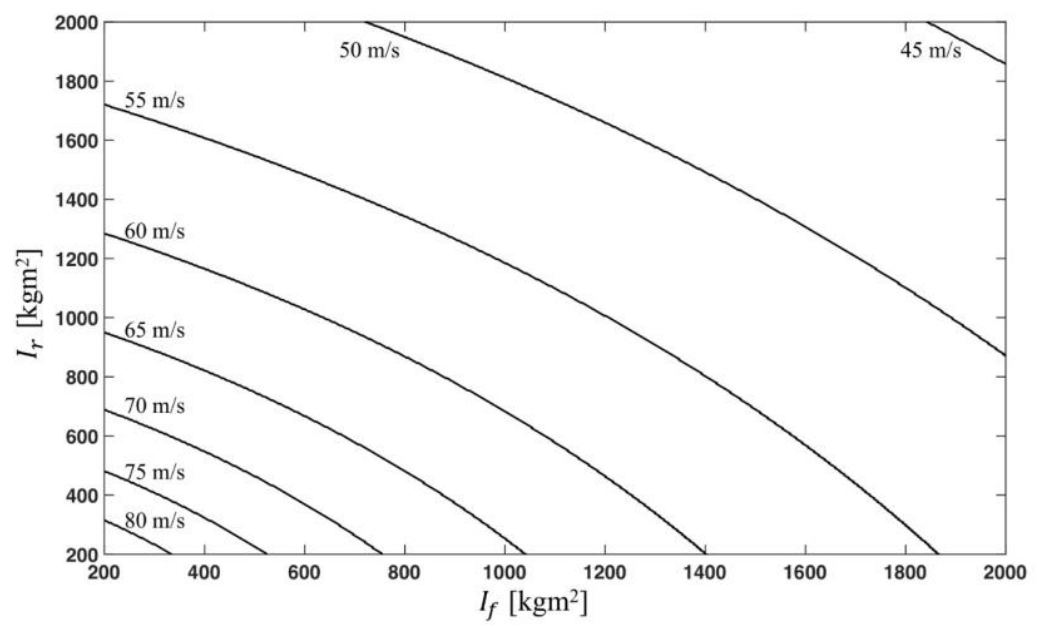

Figure 5. Change in critical speed with respect to $I_{f}$ and $I_{r}$.

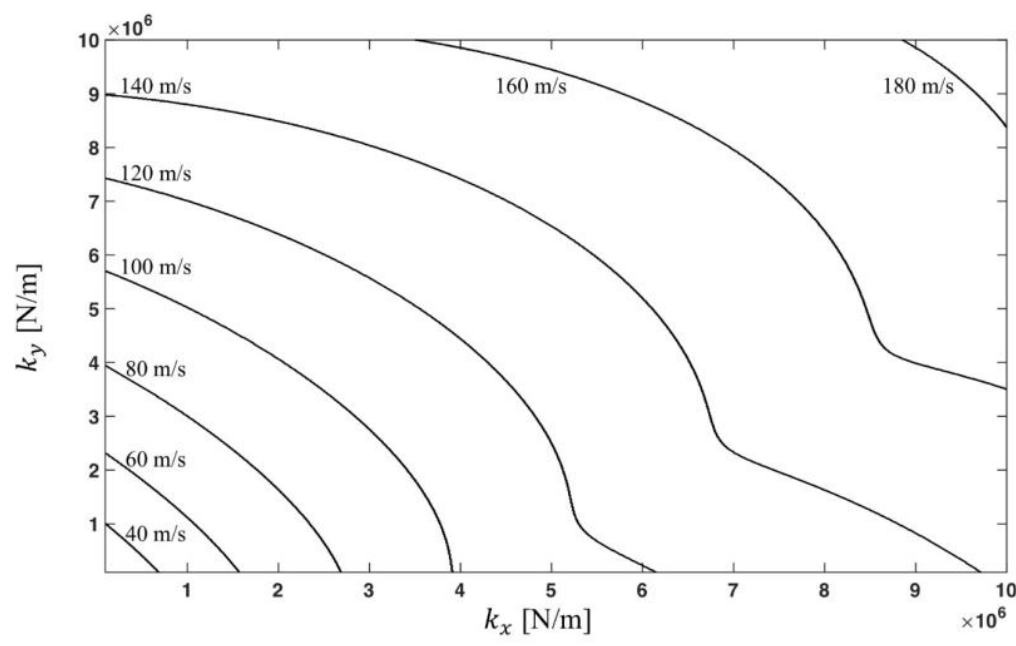

Figure 6. Change in critical speed with respect to $m_{f}$ and $m_{r}$. 


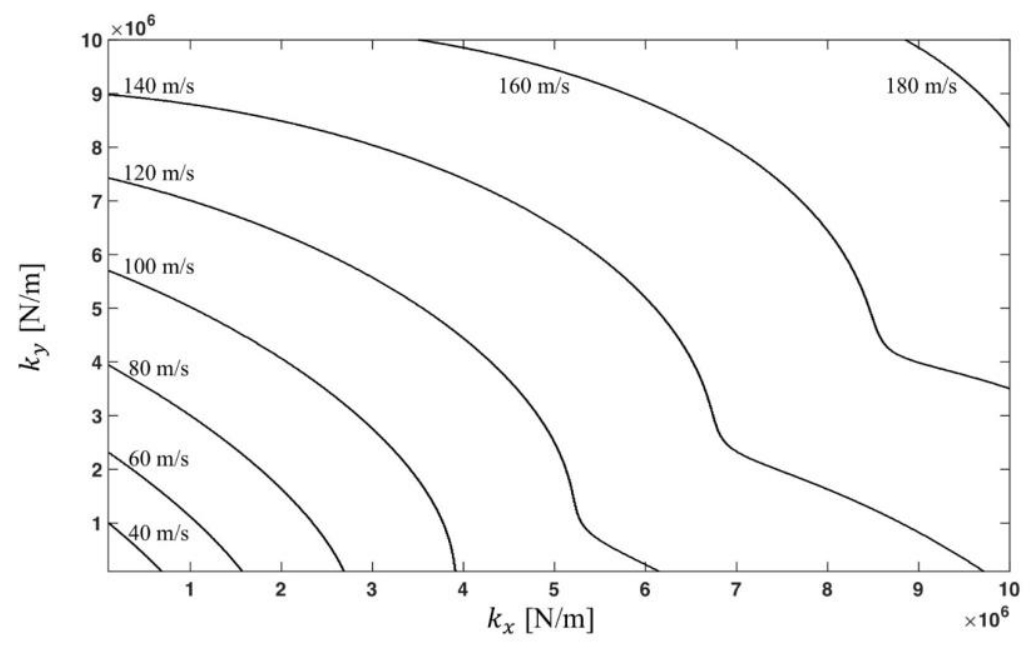

Figure 7. Change in critical speed with respect to $k_{x}$ and $k_{y}$.

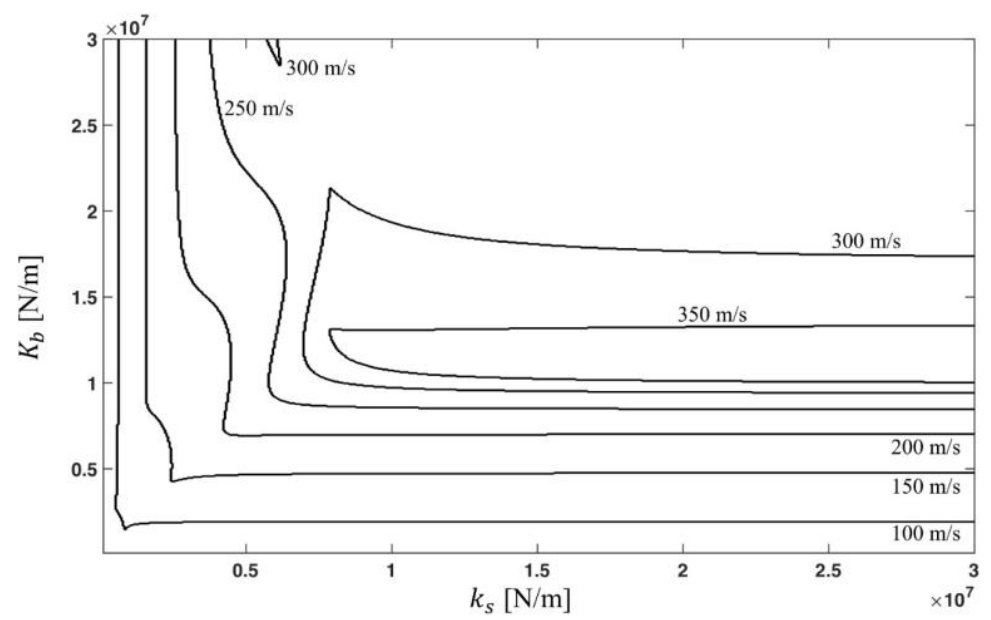

Figure 8. Change in critical speed with respect to $k_{s}$ and $K_{b}$.

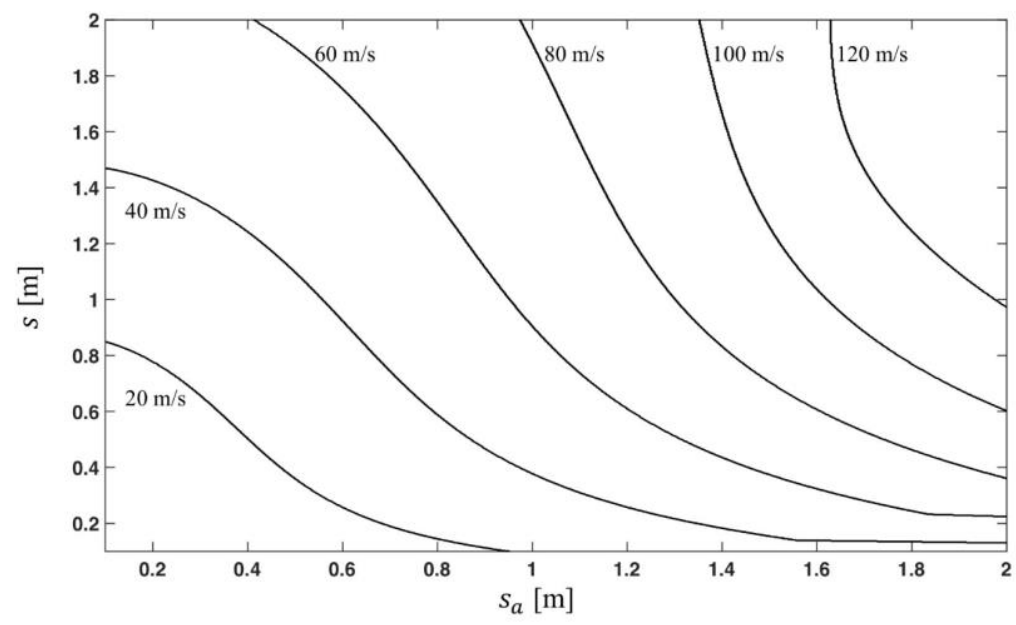

Figure 9. Change in critical speed with respect to $s_{a}$ and $s$. 


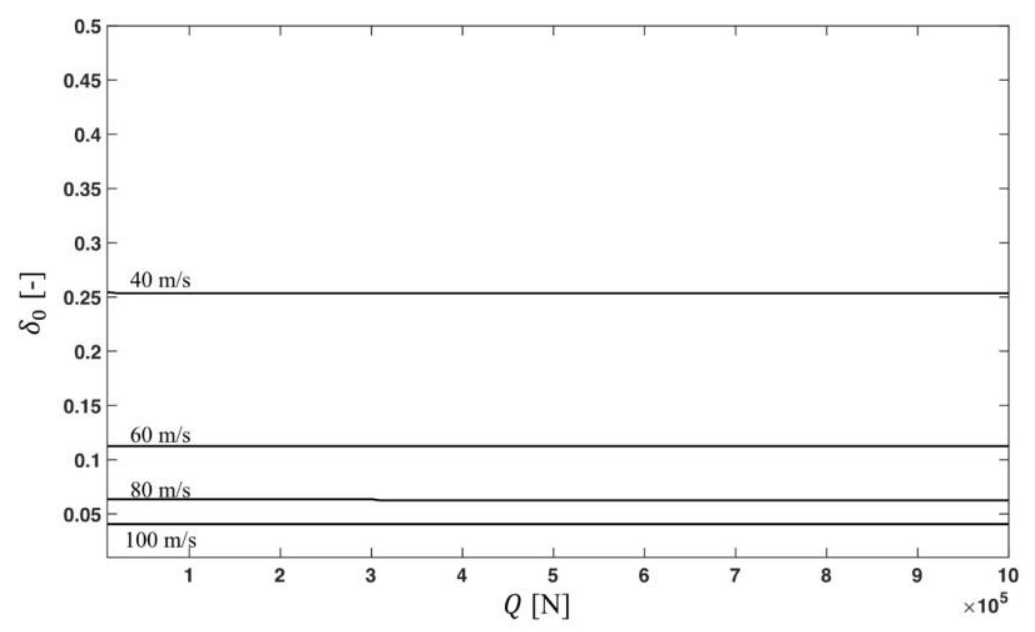

Figure 10. Change in critical speed with respect to $Q$ and $\delta_{0}$.

\section{Conclusion}

In this paper, the stability of a two-axle bogie with elastically connected wheelsets is investigated. First, a mathematical model of the bogie is developed, and the nonlinear governing equations are solved numerically. Second, the nonlinear model is reduced to a linear system with the assumption of a simpler contact model, and the time domain responses are obtained analytically. A good match between numerical and analytical solutions is observed, especially for the stable state of the bogie, thus it is shown that the linear model can represent the dynamics of the nonlinear model successfully. Third, the eigenvalue problem is formulated from the linear model and the effect of bogie speed on stability is observed. It is shown that eigenvalues are speed dependent, hence the stability of the system can be disturbed above critical speeds. Finally, a parametric study is carried out, and effects of system parameters, such as geometric dimensions, inertial terms, elastic properties, etc., on the stability of the bogie are investigated in details. Even though the model proposed in the current paper is simple, it is useful to present the trends in terms of parameter changes that lead to unstable motion.

In this paper, observe that the wheels are assumed to have a purely coned profiles whereas the rails are defined as a single point. Therefore, complex contact cases, such as two-point or conformal contact do not emerge. The model proposed in this paper can be extended through a complicated wheel/rail contact interface modeling, where both the wheel and rail profile geometries are considered. Furthermore, the degree of freedom of the model can be increased by considering a wagon body, which is attached to the developed bogie model through the secondary suspension system. Hence, the critical speed estimations could reveal more realistic results.

\section{Acknowledgement}

The author acknowledges the Scientific Research Projects Unit of Istanbul Technical University for supporting this fundamental study.

\section{References}

[1] G. Stephenson, "Observations on edge and tram railways," 1821.

[2] A. H. Wickens, "The dynamics of railway vehicles on straight track: Fundamental considerations of lateral stability," Proc. Inst. Mech. Eng., vol. 180, no. 6, pp. 29-44, 1965.

[3] A. H. Wickens, "The dynamic stability of railway vehicle wheelsets and bogies having profiled wheels," Int. J. Solids Struct., vol. 1, no. 3, pp. 319-341, 1965. 
[4] S. Y. Lee and Y. C. Cheng, "Hunting stability analysis of high-speed railway vehicle trucks on tangent tracks," J. Sound Vib., vol. 282, no. 3, pp. 881-898, 2005.

[5] S. Y. Lee and Y. C. Cheng, "A new dynamic model of high-speed railway vehicle moving on curved tracks," J. Vib. Acoust., vol. 130, no. 1, 2008.

[6] Y. C. Cheng, S. Y. Lee and H. H. Chen, "Modeling and nonlinear hunting stability analysis of highspeed railway vehicle moving on curved tracks," J. Sound. Vib., vol. 324, no. 1-2, pp. 139-160, 2009.

[7] A. A. Shabana, M. Tobaa and K. E. Zaazaa, "Effect of the wheel geometric design on the nonlinear dynamics of railroad vehicles," J. Mech. Des., vol. 128, no. 5, pp. 1130-1140, 2006.

[8] P. Kim, J. Jung and J. Seok, "A parametric dynamic study on hunting stability of full dual-bogie railway vehicle," Int. J. Precis. Eng. Manuf., vol. 12, no. 3, pp. 505-519, 2011.

[9] M. Taheri and M. Ahmedian, "Investigation of parameters influencing hunting performance of a railway vehicle with three-piece trucks," in 2015 Joint Rail Conference, San Jose, California, USA, 2015.

[10] J. H. Park, H. I. Koh and N. P. Kim, "Parametric study of lateral stability for a railway vehicle," J. Mech. Sci. Technol., vol. 25, no. 7, pp. 1657-1666, 2011.

[11] Y. Nath and K. Jayadev, "Influence of yaw stiffness on the nonlinear dynamics of railway wheelset," Commun. Nonlinear Sci. Numer. Simul., vol. 10, no. 2, pp. 179-190, 2005.

[12] S. Z. Meymand, A. Keylin, M. Ahmadian, "A survey of wheel-rail contact models for rail vehicles," Vehicle System Dynamics, vol. 54, no. 3, pp. 386-428, 2016.

[13] J. J. Kalker, "Wheel-rail rolling contact theory," Wear, vol. 144, no. 1-2, pp. 243-261, 1991.

[14] J. J. Kalker, Rolling Contact Phenomena. Vienna: Springer, 2000.

[15] J. J. Kalker, "Simplified theory of rolling contact," Delft Progress Rep., Delft Univ. Press, pp. 1- 10, 1973.

[16] J. J. Kalker, Three-dimensional elastic bodies in rolling contact. Kluwer Academic Publishers, Dordrech, 1990.

[17]H. Hertz, "Über die Berührung fester elastischer Körper," Journal für die Reine und Angewandte Mathematik, vol. 92, pp. 156-171, 1882.

[18] A. A. Shabana, M. Berzeri and J. R. Sany, "Numerical procedure for the simulation of wheel/rail contact dynamics," J. Dyn. Syst. Meas. Contr., vol. 123, no. 2, pp. 168-178, 2001.

[19] J. Klingel, "Über den Lauf der Eisenbahnwagen auf gerader Bahn," Organ für die Fortschritte des Eisenbahnwessens, vol. 20, no. 4, pp.113-123, 1883.

[20] A. M. Whitman, “On the lateral stability of a flexible truck," J. Dyn. Syst. Meas. Contr., vol. 105, no. 2, pp. 120-125, 1983.

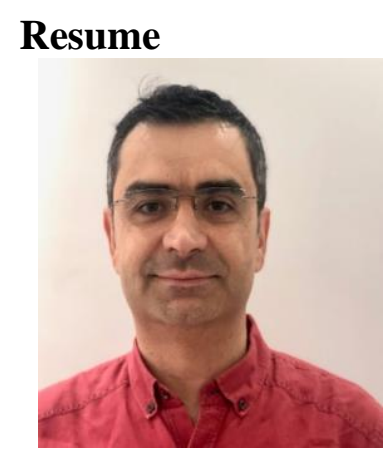

Ethics Statement:

Author confirm that the article is original, there is no plagiarism issue.

\section{Osman Taha SEN}

He received his B.Sc. and M.Sc. degrees from the Mechanical Engineering Department of Istanbul Technical University in 2005 and 2007, respectively. He then started his Ph.D. studies at the Ohio State University in 2008 and received his degree in 2012. He currently is serving as a faculty at the Mechanical Engineering Department of Istanbul Technical University. His research interests include mechanical vibrations, acoustics, nonlinear dynamics, signal processing, road/rail vehicle dynamics.

E-mail: senos@itu.edu.tr 